\title{
Interferon- $\alpha$ mediates human beta cell HLA class I overexpression, endoplasmic reticulum stress and apoptosis, three hallmarks of early human type 1 diabetes
}

\author{
Laura Marroqui ${ }^{1} \cdot$ Reinaldo S. Dos Santos $^{1} \cdot$ Anne Op de beeck ${ }^{1}$. \\ Alexandra Coomans de Brachène ${ }^{1} \cdot$ Lorella Marselli $^{2}$ • Piero Marchetti ${ }^{2}$. \\ Decio L. Eizirik ${ }^{1}$
}

Received: 19 September 2016/Accepted: 13 December 2016 /Published online: 6 January 2017

(C) Springer-Verlag Berlin Heidelberg 2017

\begin{abstract}
Aims/hypothesis Three hallmarks of the pancreatic islets in early human type 1 diabetes are overexpression of HLA class I, endoplasmic reticulum (ER) stress and beta cell apoptosis. The mediators of these phenomena remain to be defined. The type I interferon IFN $\alpha$ is expressed in human islets from type 1 diabetes patients and mediates HLA class I overexpression. We presently evaluated the mechanisms involved in IFN $\alpha$ induced HLA class I expression in human beta cells and determined whether this cytokine contributes to ER stress and apoptosis.

Methods IFN $\alpha$-induced inflammation, ER stress and apoptosis were evaluated by RT-PCR, western blot, immunofluorescence and nuclear dyes, and proteins involved in type I interferon signalling were inhibited by small interfering RNAs. All experiments were performed in human islets or human EndoC- $\beta \mathrm{H} 1$ cells.
\end{abstract}

Laura Marroqui and Reinaldo S. Dos Santos contributed equally to the study.

Electronic supplementary material The online version of this article (doi:10.1007/s00125-016-4201-3) contains peer-reviewed but unedited supplementary material, which is available to authorised users.

Laura Marroqui

lmarroqu@ulb.ac.be

Decio L. Eizirik

deizirik@ulb.ac.be

1 ULB Center for Diabetes Research, Campus Erasme, Université Libre de Bruxelles, Route de Lennik, 808-CP618, B-1070 Brussels, Belgium

2 Department of Clinical and Experimental Medicine, University of Pisa, Pisa, Italy
Results IFN $\alpha$ upregulates HLA class I, inflammation and ER stress markers in human beta cells via activation of the candidate gene $T Y K 2$, and the transcription factors signal transducer and activator of transcription 2 and IFN regulatory factor 9 . Furthermore, it acts synergistically with IL-1 $\beta$ to induce beta cell apoptosis.

Conclusions/interpretation The innate immune effects induced by IFN $\alpha$ may induce and amplify the adaptive immune response against human beta cells, indicating that IFN $\alpha$ has a central role in the early phases of diabetes.

Keywords Apoptosis $\cdot$ ER stress $\cdot$ IFN $\alpha \cdot$ MHC class I Pancreatic beta cells $\cdot$ Pancreatic islets $\cdot$ Type 1 diabetes $\cdot$ Type I IFN signalling

\section{Abbreviations}

ATF3 Activating transcription factor 3

BIP Binding immunoglobulin protein

CHOP C/EBP homologous protein

CXCL10 C-X-C motif chemokine ligand 10

eIF2 Eukaryotic initiation factor 2

ER Endoplasmic reticulum

HO Hoechst 33342

IFNAR1 IFN $\alpha / \beta$ receptor

IRF9 IFN regulatory factor 9

ISG IFN-stimulated gene

JAK Janus kinase

PI Propidium iodide

PIC Polyinosinic-polycytidylic acid

siCTRL siRNA control

siRNA Small interfering RNA

STAT Signal transducer and activator of transcription

TYK2 Tyrosine kinase 2 
TUDCA Tauroursodeoxycholic acid

USP18 Ubiquitin-specific peptidase 18

XBP1 X-box binding protein 1

XBP1s Spliced isoform of XBP1

\section{Introduction}

Three hallmarks of the pancreatic islets in early human type 1 diabetes and in mouse models of the disease are overexpression of HLA class I [1, 2], presence of markers of endoplasmic reticulum (ER) stress [3-5] and beta cell apoptosis [6]. The mediator(s) of these phenomena, however, remain(s) to be defined.

The cytokine IFN $\alpha$, a member of the type I IFN family, is expressed in human islets from patients with type 1 diabetes [7-10] and in the pancreas of NOD mice [11-13]. Children genetically at risk for type 1 diabetes present a type I IFNinducible transcriptional signature that precedes the development of autoantibodies $[14,15]$, and IFN $\alpha$ plays a major role as mediator of HLA class overexpression in human islet cells, a key event in early type 1 diabetes $[16,17]$. Laser-captured islets obtained from living donors with recent onset type 1 diabetes showed a significant increase in nearly $50 \%$ of the IFN-stimulated genes (ISGs) evaluated [18]. Neutralisation of the IFN $\alpha / \beta$ receptor (IFNAR1) with monoclonal antibodies prevents diabetes in NOD mice $[13,19]$ and self-reactive antibodies targeting type I IFNs - particularly IFN $\alpha$-are associated with protection against type 1 diabetes in patients with mutations in the thymus transcription factor autoimmune regulator (AIRE) [20]. It is surprising that very few studies have investigated the direct effects of this cytokine in pancreatic beta cells [21-23].

We presently tested the hypothesis that IFN $\alpha$ is a common mediator of HLA class I overexpression, ER stress and beta cell apoptosis in early type 1 diabetes, and evaluated the signal transduction mediating these effects. All experiments were performed in human pancreatic islets and the human insulinproducing cell line EndoC- $\beta \mathrm{H} 1$ [24], increasing their translational potential [25-28]. The data obtained indicate that IFN $\alpha$ is a crucial mediator of excessive inflammation and ER stress in the early steps of type 1 diabetes.

\section{Methods}

Culture of human EndoC- $\beta \mathrm{H} 1$ beta cells and human islets, and cell treatments The human beta cell line EndoC- $\beta \mathrm{H} 1$ (kindly provided by R. Scharfmann, Centre de Recherche de l'Institut du Cerveau et de la Moelle Épinière, Paris, France) was cultured in Matrigel-fibronectin-coated plates [24]. MycoAlert Mycoplasma Detection kit (Lonza, Basel, Switzerland) was used to test for mycoplasma infection.
EndoC- $\beta \mathrm{H} 1$ cells have been shown to be free of mycoplasma infection.

Human islets from 12 non-diabetic organ donors (ESM Table 1) were isolated with the agreement of the local Ethical Committee in Pisa, Italy and sent to Brussels for experiments (see ESM Methods). Human islets or EndoC- $\beta \mathrm{H} 1$ cells were exposed to cytokines or other agents as described in ESM Methods [23, 26].

RNA interference Conditions for small interfering RNA (siRNA) transfection using Lipofectamine RNAiMAX lipid reagent (Invitrogen, Carlsbad, CA, USA) and optimal siRNA concentration (30 nmol/l) were established previously [29]. Allstars Negative Control siRNA (Qiagen, Venlo, the Netherlands) was used as a negative control (siCTRL); see ESM Methods for further details. siRNAs against TYK2, STAT1, STAT2, IRF9, USP18, PTPN2, and CHOP were used in this study (a list with further information is provided in ESM Table 2).

Assessment of cell viability Cell viability was determined after staining with the DNA-binding dyes Hoechst 33342 (HO) and propidium iodide (PI) as described [29, 30]. See ESM Methods.

mRNA extraction and real-time PCR Poly $(\mathrm{A})^{+}$mRNA extraction was performed using Dynabeads mRNA DIRECT kit (Invitrogen) in accordance with the manufacturer's instructions; reverse transcription was carried out as described [23]. Quantitative real-time PCR was performed using SYBR Green and the data were compared with a standard curve [31]. Expression values were corrected by the housekeeping gene $\beta$-actin, as its expression is not modified under the conditions used in this study [23] (data not shown). A list with the primers used in this study is provided in ESM Table 3.

Western blot analysis, immunofluorescence and flow cytometry Western blotting was performed as described [23]. Briefly, cells were washed with cold PBS and lysed in Laemmli or RIPA buffer. Immunoblot analysis was performed with antibodies against signal transducer and activator of transcription (STAT) 1-3 and their phosphorylated forms, MHC class I, interferon regulatory factor 9 (IRF9), activating transcription factor 3 (ATF3), X-box binding protein 1 (XBP1), phosphorylated eukaryotic initiation factor 2 (p-eIF2 $\alpha$ ), binding immunoglobulin protein (BIP), insulin (all at 1:1000 dilution) and $\alpha$-tubulin (1:5000; see ESM Table 4). Peroxidaseconjugated antibodies (1:5000) were used as secondary antibodies. SuperSignal West Femto chemiluminescent substrate (Thermo Scientific, Rockford, IL, USA) and ChemiDoc XRS+ (Bio-Rad Laboratories, Temse, Belgium) were used to detect bands and Image Lab software (version 3.0, Bio- 
Rad Laboratories, Temse, Belgium) was used for densitometry analysis.

Immunofluorescence was performed as described [23]. Briefly, cells were plated on polylysine-coated coverslips, treated with intracellular IFN $\alpha$ for $24 \mathrm{~h}$ and fixed with $4 \%$ paraformaldehyde. Cells were permeabilised and incubated with rabbit anti-MHC class I (W6/32) (1:1000) or mouse monoclonal anti-insulin (1:1000). Alexa Fluor-conjugated secondary antibodies were used (see ESM Table 4). After nuclear staining with $\mathrm{HO}$, coverslips were mounted with fluorescent mounting medium (Dako, Carpintera, CA, USA) and immunofluorescence was visualised on a Zeiss microscope equipped with a camera (Zeiss-Vision, Munich, Germany). Images were acquired at $\times 20$ or $\times 40$ magnification and analysed using AxiVision software (version 4.7.2; ZeissVision, Munich, Germany). Images (magnification $\times 20$ ) were quantified using FIJI software (version 2.0; https://fiji.sc) and calculated as (mean of fluorescence / number of cells) $\times 100$.

The same protocol used for immunofluorescence, but without permeabilisation, was used for flow cytometry. Cells were detached by a mild Accutase (Sigma-Aldrich, Schnelldorf, Germany) treatment and then suspended in 2\% paraformaldehyde and EDTA-containing PBS and analysed by flow cytometry (FacsCanto; BD Biosciences, San Jose, CA, USA). Analysis was performed using FACSDiva software version 1.0 (BD Biosciences, San Jose, CA, USA). The cellular populations were selected based on size and cell granularity and were analysed for BV421 fluorescence.

Antibodies have been previously validated by our group.

Statistical analysis Data are shown as means \pm SEM or presented as box plots indicating lower quartile, median and higher quartile, with whiskers representing the range of the remaining data points. Comparisons were performed by twotailed paired $t$ test or by ANOVA followed by paired $t$ test with Bonferroni correction, as indicated. Results with $p<0.05$ were considered significant.

\section{Results}

IFN $\alpha$ activates STAT pathways that increase expression of MHC class I protein and inflammatory markers in human beta cells IFN $\alpha$ activated STAT1, STAT2 and STAT3; the maximum effect was observed at $1-2 \mathrm{~h}$ post treatment and returned to baseline by $24 \mathrm{~h}$ (Fig. 1a). At later time points ( 8 and $24 \mathrm{~h}$ ), IFN $\alpha$ induced the expression of IRF9, an essential protein for IFN $\alpha$ signal transduction [32] (Fig. 1a), and of MHC class I expression at mRNA and protein levels in EndoC- $\beta \mathrm{H} 1$ cells and dispersed human islets (Fig. 1b-d, g). IFN $\alpha$ also increased, at 4-8 h, expression of mRNAs encoding for the chemokine $\mathrm{C}-\mathrm{X}-\mathrm{C}$ motif chemokine ligand

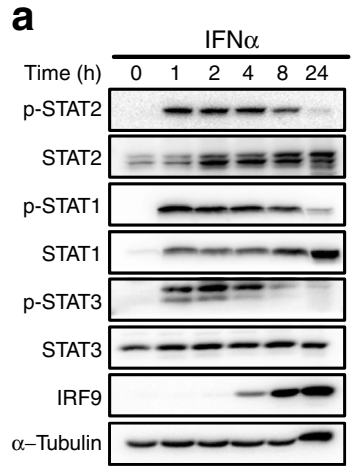

b
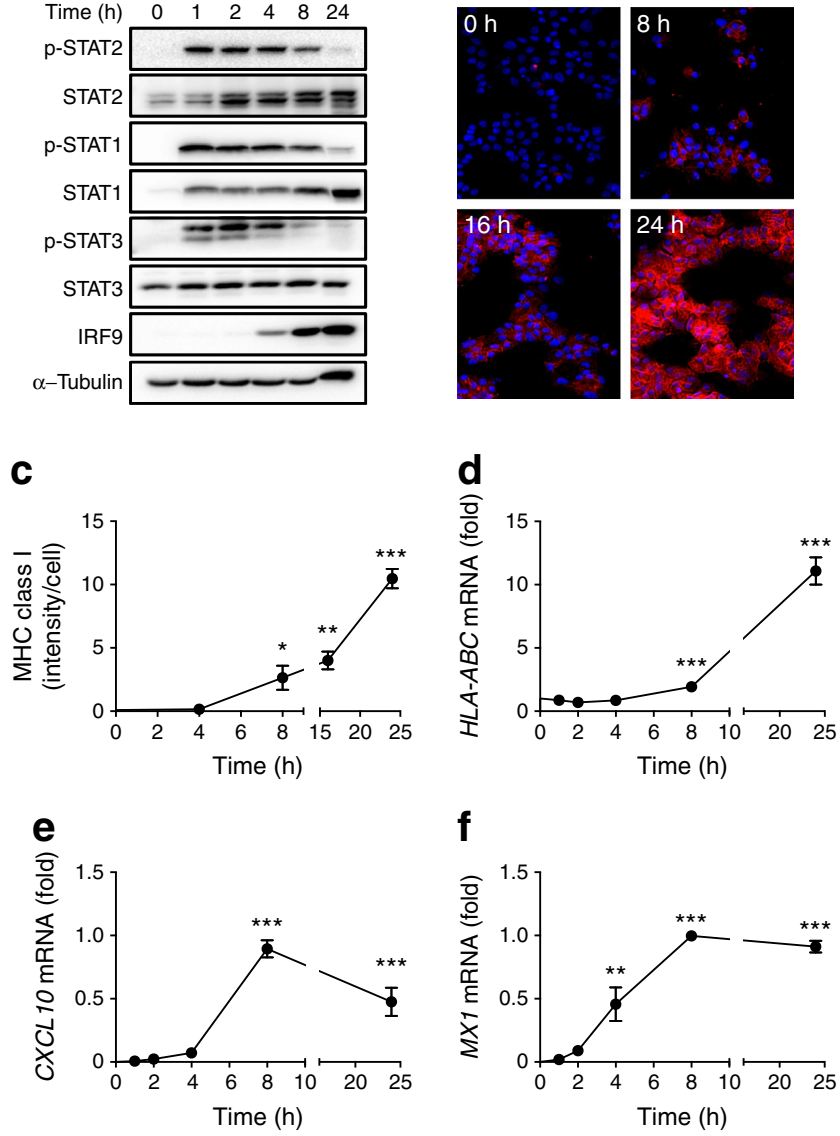

f

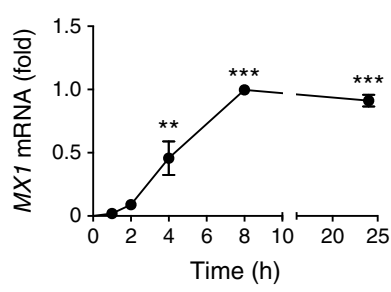

g

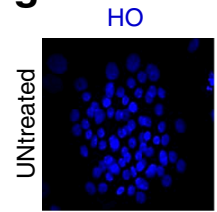

Insulin
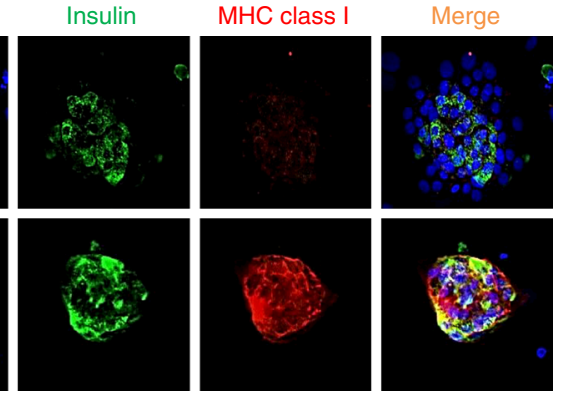

Fig. 1 IFN $\alpha$ activates STAT pathways and increases inflammatory and innate immune response markers and MHC class I expression in human beta cells. EndoC- $\beta$ H1 (a-f) or dispersed human islets (g) were left untreated or were treated with IFN $\alpha(2000 \mathrm{U} / \mathrm{ml})$ for $1-24 \mathrm{~h}(\mathbf{a}-\mathbf{f})$ or $24 \mathrm{~h}$ (g). (a) Protein expression was measured by western blot. Images are representative of three independent experiments. (b, c) MHC class I protein expression was analysed by immunocytochemistry (ICC). Representative images of three independent experiments (magnification $\times 40)(\mathbf{b})$ and quantification (c) is shown. $(\mathbf{d}-\mathbf{f})$ mRNA expression of $H L A-A B C(\mathbf{d}), C X C L 10$ (e) and $M X 1$ (f) was analysed by RT-PCR and normalised by $\beta$-actin. In (d), values were normalised by control $(0 \mathrm{~h})$, considered as 1 . In (e) and (f), values were normalised by the highest value of each experiment (considered as 1 ). Results are means \pm SEM of three to six independent experiments. ${ }^{*} p<0.05$, $* * p<0.01$ and $* * * p<0.001$ vs untreated (ANOVA). (g) ICC of MHC class I (red), insulin (green) and $\mathrm{HO}$ (blue) was performed to confirm MHC class I expression in two dispersed human islet preparations (magnification $\times 40$ ) 
10 (CXCL10) and the antiviral protein MX dynamin like GTPase 1 (MX1) (Fig. 1e, f).

IFN $\alpha$ and IFN $\gamma$ similarly induced MHC class I expression (around 15-fold increase above basal), while IL-1 $\beta$ showed no effect (ESM Fig. 1b, c) and polyinosinic-polycytidylic acid (PIC) only a twofold-increased effect. Expression of MHC class I was not associated with apoptosis in EndoC- $\beta \mathrm{H} 1$ cells (ESM Fig. 1a).

Flow cytometry analysis showed that IFN $\alpha$ induced a dose-dependent (starting at $2 \mathrm{U} / \mathrm{ml}$ ) increase in MHC class I surface expression (ESM Fig. 2a-c) and $H L A-A B C$ and CXCL10 (ESM Fig. 2d, e) mRNA expression.

IFN $\alpha$ increases ER stress markers in human beta cells Exposure of EndoC- $\beta \mathrm{H} 1$ cells to IFN $\alpha$ for $24 \mathrm{~h}$ upregulated expression of mRNAs and proteins for the following ER stress markers (an outline of the evaluated ER stress markers is depicted in Fig. 2a): DNA damage inducible transcript 3 (encoded by $C H O P$, also known as DDIT3) (Fig. 2b), ATF3 (Fig. 2c, f, h), heat shock protein family A (Hsp70) member 5 (encoded by BIP, also known as HSPA5) (Fig. 2d, f, i), spliced isoform of XBP1 (XBP1s, encoded by XBP1s; Fig. 2e, f, j) and phosphorylated eIF2 $\alpha$ (Fig. 2f, g). Expression of $C H O P$ was also induced in EndoC- $\beta \mathrm{H} 1$ cells by $20-200 \mathrm{U} / \mathrm{ml}$ of IFN $\alpha$ (ESM Fig. 3). There was an early ( $1 \mathrm{~h})$ and transitory increase in phosphorylated EIF $2 \alpha$ and its downstream protein ATF3 (Fig. 2f-h). In contrast, XBP1s and BIP protein expression was augmented after $4 \mathrm{~h}$ and remained increased until 24 h (Fig. 2f, i, j).

IFN $\alpha$-induced inflammation and ER stress response is abolished by tyrosine kinase 2 knockdown in human beta cells $T Y K 2$, a candidate gene for type 1 diabetes, contributes to the activation of the type I IFN pathway and regulation of MHC class I expression in human beta cells [23]. Tyrosine kinase 2 (TYK2) knockdown prevented IFN $\alpha$-induced MHC class I protein expression in EndoC- $\beta \mathrm{H} 1$ cells (ESM Fig. 4a, c) and dispersed human islets (ESM Fig. 4b, d) and also partially or completely prevented induction of CXCL10 (Fig. 3a, g), $M X 1$ (Fig. 3b, h) and the ER stress markers $C H O P$
Fig. 2 IFN $\alpha$ increases ER stress markers in EndoC- $\beta \mathrm{H} 1$ cells. (a) Schematic representation of the ER stress markers measured. IRE1, inositol-requiring protein 1; PERK, protein kinase RNA-like endoplasmic reticulum kinase. (b-j) EndoC- $\beta \mathrm{H} 1$ cells were left untreated or were treated with $\operatorname{IFN} \alpha(2000 \mathrm{U} / \mathrm{ml}) . \mathrm{mRNA}$ expression of $C H O P(\mathbf{b}), A T F 3$ (c), BIP (d) and XBP1s (e) was analysed by RT-PCR, normalised by $\beta$-actin and then by the highest value of each experiment (considered as 1). Protein expression was measured by western blotting and representative images of four independent experiments are shown (f). Densitometry results are shown for p-EIF $2 \alpha(\mathbf{g})$, ATF3 (h), BIP (i) and XBP1s (j). Values were normalised by $\alpha$-tubulin ( $\alpha$ tub), and then by the highest value of each experiment (considered as 1). Results are means \pm SEM of four to six independent experiments. $* p<0.05$, $* * p<0.01$ and $* * * p<0.001$ vs untreated (ANOVA)
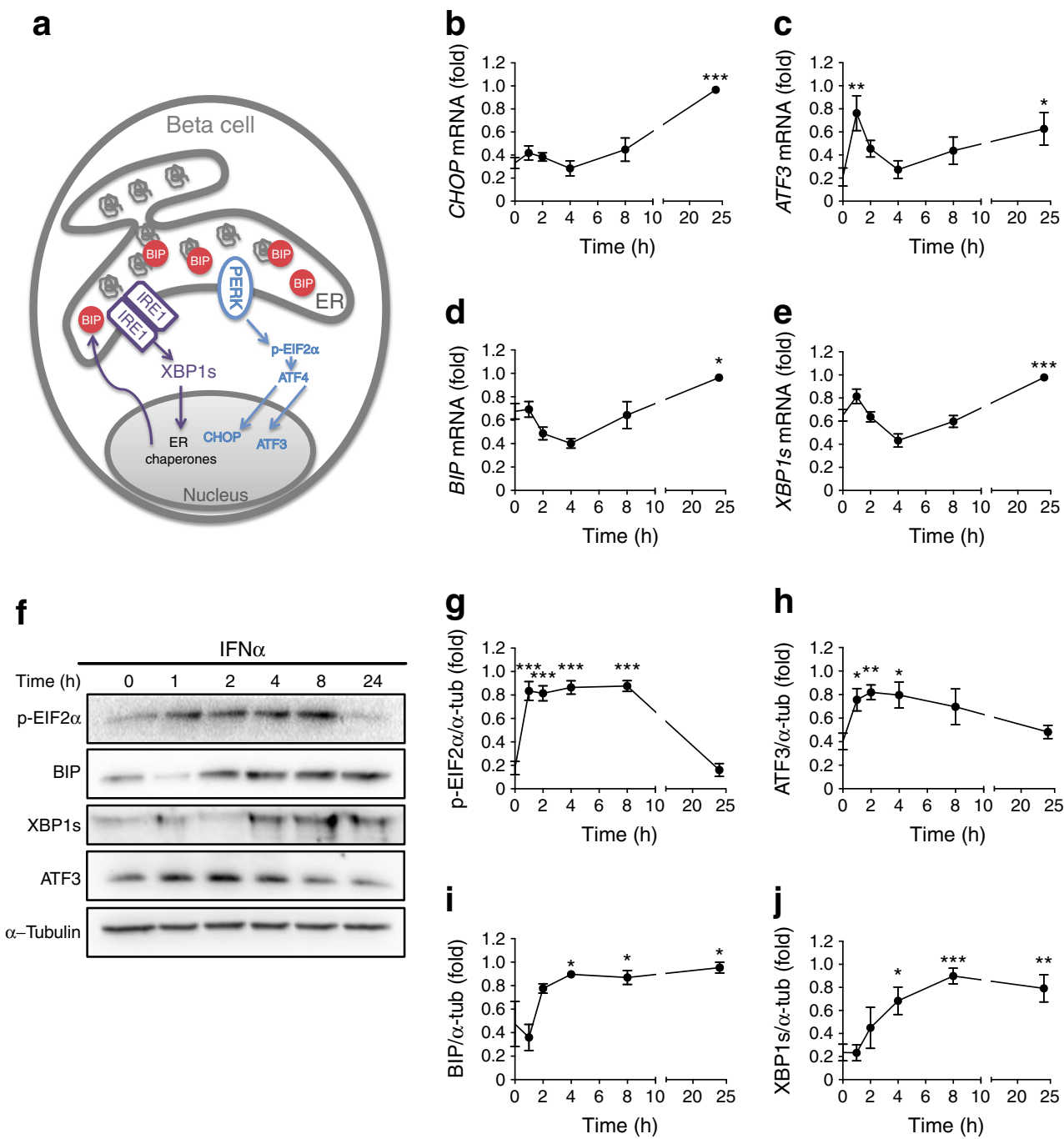
Fig. 3 TYK2 inhibition prevents IFN $\alpha$-induced inflammation and ER stress markers in human beta cells. EndoC- $\beta \mathrm{H} 1$ cells $(\mathbf{a}-\mathbf{f})$ and dispersed human islets $(\mathbf{g}-\mathbf{l})$ were transfected with siCTRL (black bars) or with siRNA targeting TYK2 (white bars). Cells were left untreated or were treated with IFN $\alpha(2000 \mathrm{U} / \mathrm{ml})$ for $24 \mathrm{~h}$ (EndoC- $\beta \mathrm{H} 1$ cells) or 24 and $48 \mathrm{~h}$ (dispersed human islets). mRNA expression of $C X C L 10(\mathbf{a}, \mathbf{g})$, $M X 1(\mathbf{b}, \mathbf{h}), C H O P(\mathbf{c}, \mathbf{i}), A T F 3$ $(\mathbf{d}, \mathbf{j}), B I P(\mathbf{e}, \mathbf{k})$ and $X B P 1 s(\mathbf{f}, \mathbf{l})$ was analysed by RT-PCR and normalised by $\beta$-actin. In (a-h), values were normalised by the highest value of each experiment (considered as 1). In (i-l), values were normalised by siCTRL (black bars, non-treated), considered as 1 . Results are means \pm SEM of three or four independent experiments. $* p<0.05, * * p<0.01$ and $* * * p<0.001$ vs untreated and transfected with the same siRNA; ${ }^{\dagger} p<0.05,{ }^{\dagger} p<0.01$ and ${ }^{\dagger} p<0.001$, as indicated by bars (ANOVA) a

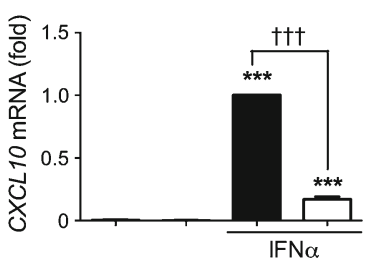

d

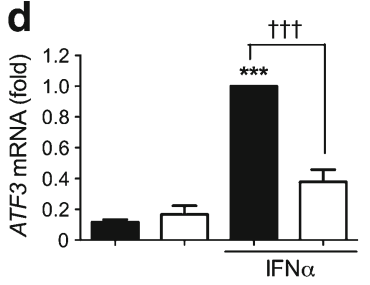

9

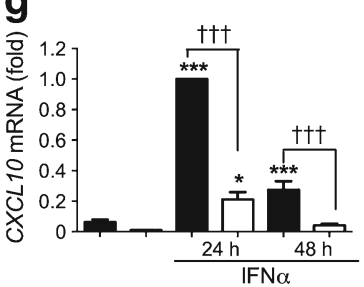

j

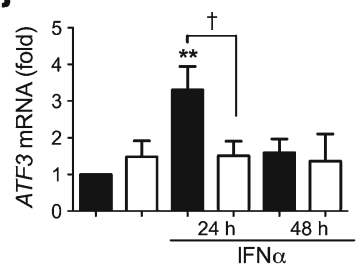

b

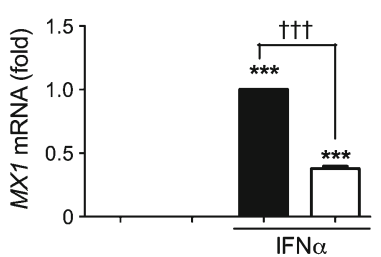

e

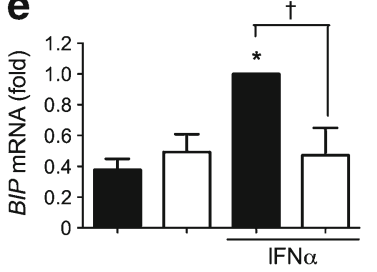

h

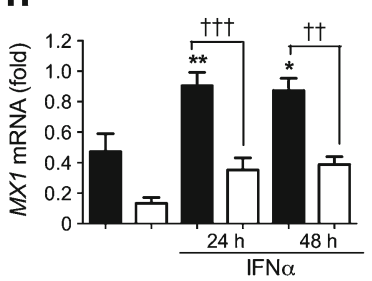

K

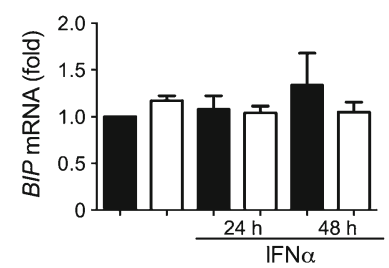

C

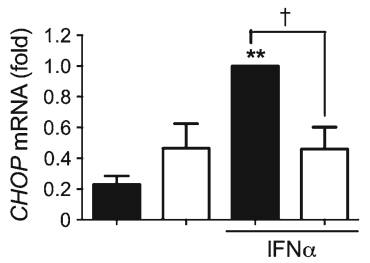

f

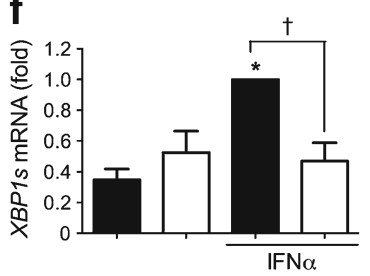

i

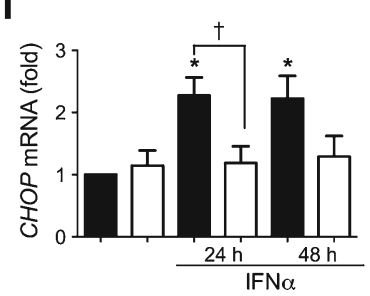

I

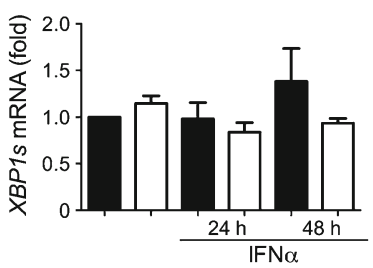

(Fig. 3c, i), ATF3 (Fig. 3d, j) BIP (Fig. 3e, k) and $X B P 1 s$ (Fig. 3f, 1) by IFN $\alpha$.

STAT2 and IRF9, but not STAT1, are important mediators of IFN $\alpha$-induced inflammation and ER stress markers in human beta cells Type I IFN binding to its receptor activates TYK2, which in turn phosphorylates STAT1 and STAT2 [32]. Surprisingly, STAT1 knockdown $(\geq 70 \%$ at mRNA and protein levels; Fig. 4a, 1 and ESM Fig. 5a, b) failed to decrease IFN $\alpha$-induced MHC class I expression at mRNA or protein levels in EndoC- $\beta \mathrm{H} 1$ cells (Fig. $4 \mathrm{c}-\mathrm{e}$ ). This was paralleled by increased expression of CXCL10 (Fig. 4f), $M X 1$ (Fig. 4g) and ER stress markers (Fig. 4h-k), especially $C H O P$ and ATF3. STAT1 knockdown, however, prevented IFN $\gamma$-induced HLA class I and CXCL10 expression (ESM Fig. 5d, e), indicating that the level of STAT1 inhibition reached was sufficient to block its downstream effects.

Knockdown of STAT2 and double knockdown of STAT1 and 2 ( $\geq 60 \%$ and $\geq 70 \%$, respectively; Fig. $4 a, b, 1)$, almost completely prevented IFN $\alpha$-induced expression of $\mathrm{MHC}$ class I (Fig. 4c-e), CXCL10 (Fig. 4f) and MX1 (Fig. 4g), and ER stress markers (Fig. 4h-k). STAT2 knockdown led to STAT1 overactivation, and vice versa, suggesting a compensatory effect between them (Fig. 4l). This may explain the observed increment in CXCL10 and $M X 1 \mathrm{mRNA}$ expression after STAT1 knockdown. These results were confirmed in dispersed human islets (Fig. 5), where only STAT2 knockdown $(\geq 80 \%$ at $\mathrm{mRNA}$ and $\geq 50 \%$ at protein level; Fig. 5b, i) decreased IFN $\alpha$-induced inflammatory and ER stress markers (Fig. 5f-h), whereas STAT1 knockdown ( $\geq 80 \%$ at mRNA and protein levels; Fig. 5a, i) increased expression of CXCL10 (Fig. 5d) and $M X 1$ (Fig. 5e) mRNA.

STAT2 dimerises with IRF9 in the absence of STAT1; this dimer subsequently binds to the IFN-stimulated response element (ISRE) and mediates downstream signal transduction [33]. Knockdown of IRF9 ( $\geq 60 \%$ at mRNA and $\geq 80 \%$ at protein level; Fig. 6b, ESM Fig. 6) and double knockdown of STAT2 and IRF9 (Fig. 6a, b and ESM Fig. 6) decreased IFN $\alpha$-induced $H L A-A B C, C X C L 10$ and $M X 1$ (Fig. 6c-e) and ER stress markers (Fig. 6f-i) mRNA levels to the same extent as STAT2 knockdown alone, indicating that both are part of the same signalling pathway. No change in apoptotic rate was 
Fig. 4 Inhibition of STAT2 but not STAT1 prevents IFN $\alpha$ induced inflammation and expression of ER stress markers and MHC class I in EndoC- $\beta \mathrm{H} 1$ cells. EndoC- $\beta \mathrm{H} 1$ cells were transfected with siCTRL (black bars) or with siRNAs targeting STAT1 (white bars), STAT2 (lightgrey bars) and STAT1/2 (darkgrey bars). Cells were left untreated or were treated with $\operatorname{IFN} \alpha(2000 \mathrm{U} / \mathrm{ml})$ for $24 \mathrm{~h}(\mathbf{a}-\mathbf{k})$ or for different lengths of time (l). mRNA expression of STAT1 (a), STAT2 (b), HLA-ABC (c), CXCL10 (f), MXI (g), CHOP (h), $A T F 3$ (i), BIP (j) and XBP1s (k) was analysed by RT-PCR and normalised by $\beta$-actin. In (f, j, k), values were normalised by siCTRL (black bars treated with IFN $\alpha$ ), considered as 1 . (d, e) immunocytochemistry (ICC) of MHC class I (red) and HO (blue) in EndoC- $\beta \mathrm{H} 1$ cells (magnification $\times 40$ ); representative images of four independent experiments (d) and quantification (e) are shown. Results are means \pm SEM of three or four independent experiments. $* * p<0.01$ and $* * * p<0.001$ vs untreated and transfected with the same siRNA; ${ }^{\dagger} p<0.05,{ }^{\dagger \dagger} p<0.01$ and ${ }^{\dagger \dagger} p<0.001$, as indicated by bars (ANOVA). In (I), protein expression was measured by western blot; representative images of three independent experiments are shown
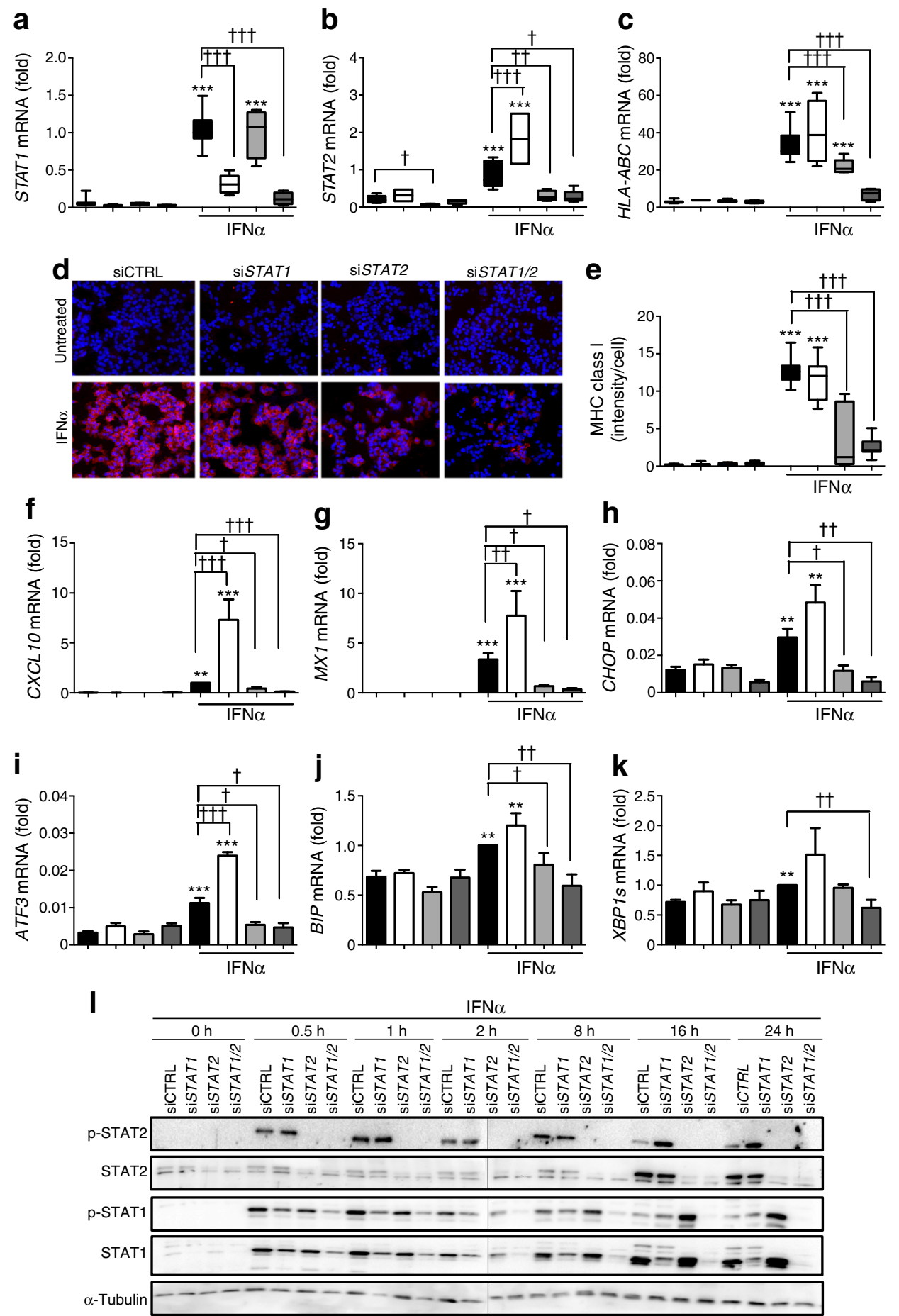

observed after knockdown of STAT1, STAT2 or IRF9 (or combinations of them) in EndoC- $\beta \mathrm{H} 1$ cells, or after knockdown of STAT1 or STAT2 in dispersed human islets treated (or not) with IFN $\alpha$ (data not shown).

Inhibition of ubiquitin-specific peptidase 18 overstimulates type I IFN signalling and increases ER stress and inflammation markers in beta cells Inhibition of ubiquitin-specific peptidase 18 (USP18) induces beta cell inflammation and apoptosis upon IFN $\alpha$ treatment by exacerbating IFN-induced phosphorylation of STATs [34]. To determine whether this would also augment IFN-induced ER stress, we knocked down USP18 in EndoC- $\beta$ H1 cells. USP18-silenced cells $(\geq 50 \%$ at mRNA level; Fig. 7a) treated with IFN $\alpha$ had increased levels of p-STAT2 and p-STAT1 (five- and twofold, respectively) (Fig. 7b-d), higher prevalence of apoptosis 


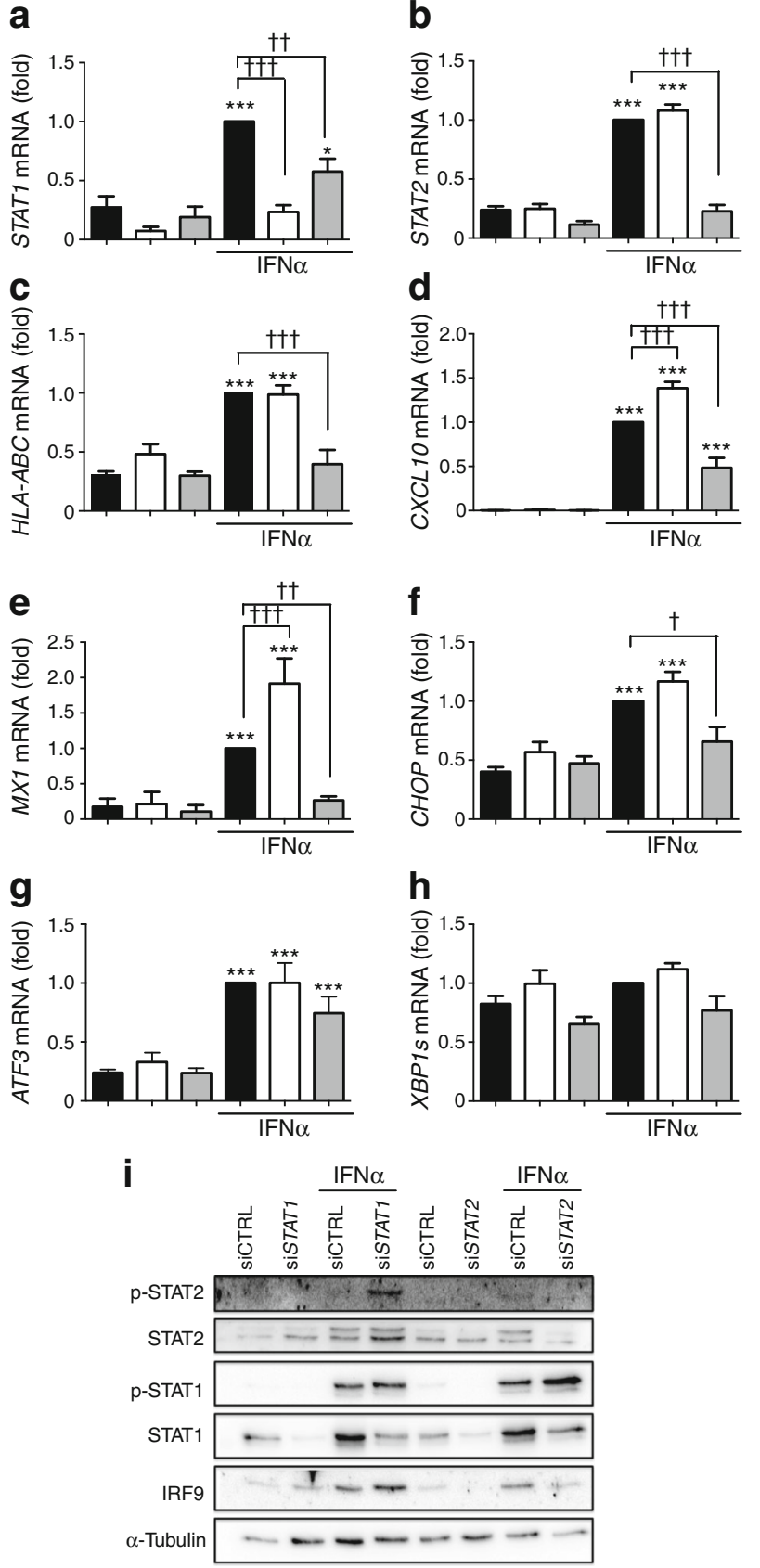

Fig. 5 Inhibition of STAT2 but not STAT1 prevents IFN $\alpha$-induced inflammation and expression of ER stress markers in dispersed human islets. Dispersed human islets were transfected with siCTRL (black bars) or with siRNAs targeting STAT1 (white bars) or STAT2 (light-grey bars). Cells were left untreated or were treated with IFN $\alpha(2000 \mathrm{U} / \mathrm{ml})$ for $24 \mathrm{~h}$. (a-h) mRNA expression of STAT1 (a), STAT2 (b), HLA-ABC (c), CXCL10 (d), MX1 (e), $C H O P(\mathbf{f}), A T F 3$ (g) and XBP1s (h) was analysed by RT-PCR and normalised by $\beta$-actin, and then normalised by siCTRL (black bars treated with IFN $\alpha$ ), considered as 1 . Results are means \pm SEM of four or five independent human islet preparations. $* p<0.05$, $* * p<0.01$ and $* * * p<0.001$ vs untreated and transfected with the same siRNA; ${ }^{\dagger} p<0.05,{ }^{\dagger \dagger} p<0.01$ and ${ }^{\dagger \dagger \dagger} p<0.001$, as indicated by bars (ANOVA). (i) Protein expression was measured by western blot; representative images of four or five independent experiments are shown
(Fig. 7e) and increased mRNA expression of $H L A-A B C$ (threefold, Fig. 7f), CXCL10 (50-fold, Fig. 7g) and $M X 1$ (threefold, Fig. 7h) and at least threefold higher ER stress markers (Fig. 7i-1), compared with control cells.

On the other hand, PTPN2 (a candidate gene for type 1 diabetes), which encodes protein tyrosine phosphatase, nonreceptor type 2, a protein phosphatase that dephosphorylates members of the Janus kinase (JAK)/STAT family but not TYK2 or STAT2 [23], did not affect IFN $\alpha$-induced $H L A$ $A B C$, inflammation and ER stress marker mRNA expression in EndoC- $\beta \mathrm{H} 1$ cells (ESM Fig. 7).

IFN $\alpha$ sensitises human beta cells against IL- $1 \beta$-induced apoptosis at least in part via increased ER stress Mild ER stress increases the expression of inflammatory mediators and sensitises rat beta cells to IL- $1 \beta$-induced apoptosis [35]. As previously observed (ESM Fig. 1), neither IFN $\alpha$ nor IL-1 $\beta$ alone induced apoptosis. The combination of both cytokines, however, increased cell death in a dose-dependent manner (Fig. 8a). IFN $\alpha$ alone, but not IL-1 $\beta$, induced the expression of HLA-ABC, MX1 and CXCL10 mRNA, even at low concentrations $(200 \mathrm{U} / \mathrm{ml})$ (Fig. 8b-d). The two cytokines only acted synergistically in the case of CXCL10 (Fig. 8c). The combination of cytokines, mainly at their highest concentrations, led to a significant increase in ER stress markers when compared with IFN $\alpha$ or IL-1 $\beta$ alone (Fig. 8e-h). Similarly to the observations made in EndoC- $\beta$ H1 cells, treatment with IFN $\alpha$ or IL- $1 \beta$ separately did not induce apoptosis in dispersed human islets, while treatment with IFN $\alpha$ plus IL-1 $\beta$ doubled beta cell death after treatment for $24 \mathrm{~h}$ (Fig. 8i).

Silencing of $C H O P$ or pre-treatment with the chemical chaperone tauroursodeoxycholic acid (TUDCA) partially prevented apoptosis induced by a combination of IFN $\alpha$ and IL- $1 \beta$ in EndoC- $\beta \mathrm{H} 1$ cells, suggesting that IFN $\alpha+\mathrm{IL}-1 \beta$-induced apoptosis is at least in part mediated by ER stress (ESM Fig. 8).

\section{Discussion}

Type 1 diabetes is a multifactorial autoimmune disease in which an individual's genetic background interacts with environmental cues, leading to islet inflammation (insulitis), amplification of this early innate immune response and, in some cases, transition to a long-term adaptive autoimmune attack against the beta cells [6]. The nature of the first components of the innate immune response and their contribution towards the transition to a full autoimmune response remains to be determined $[6,36]$.

Type I IFNs may be key links between environmental and genetic risk factors in type 1 diabetes and the triggering/ amplification of insulitis [36]. Thus, pathway analysis of type 1 diabetes candidate genes expressed in human pancreatic islets identified 'interferon signalling', 'role of JAK1, JAK2 

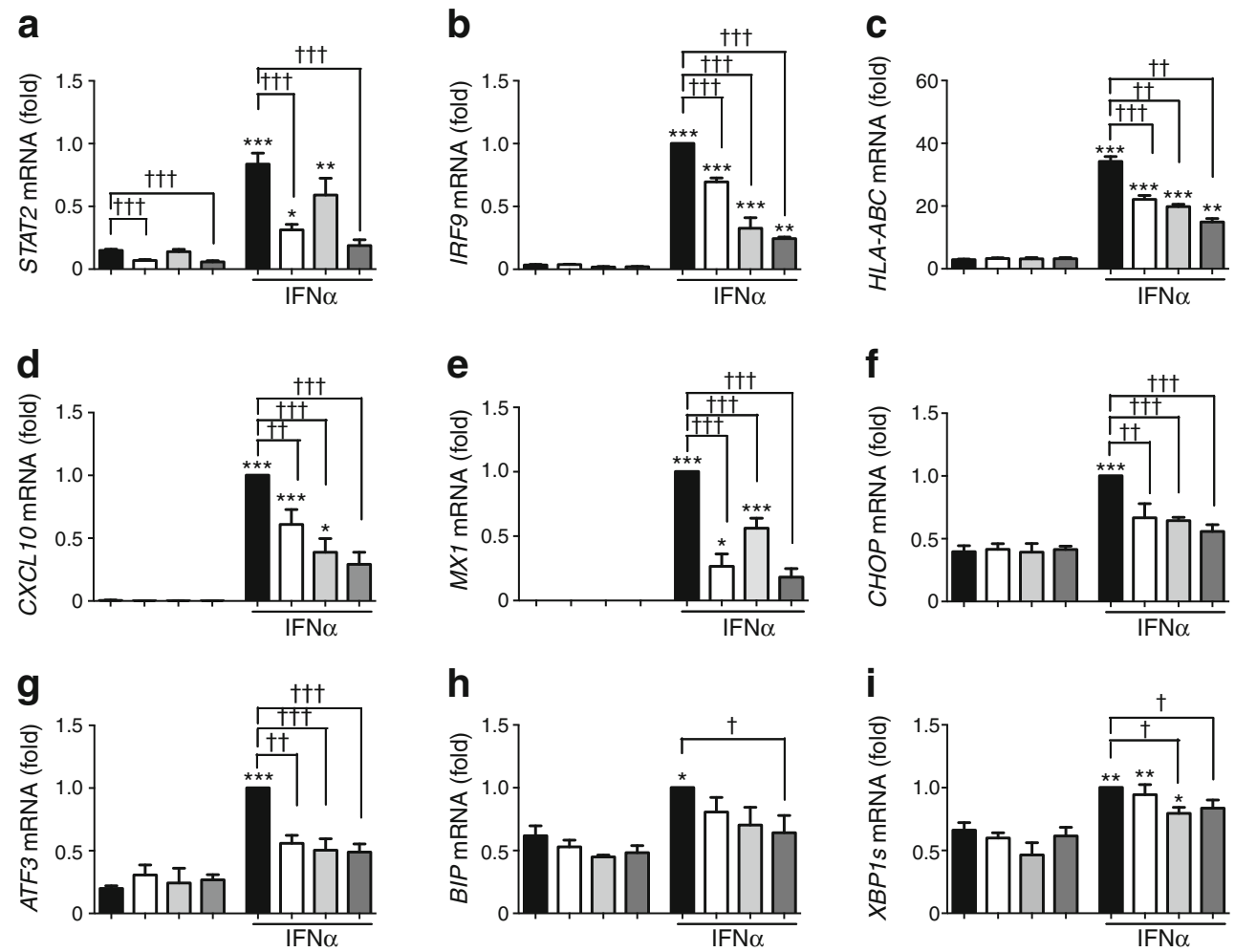

Fig. 6 Inhibition of IRF9 prevents IFN $\alpha$-induced inflammation and expression of ER stress markers in EndoC- $\beta \mathrm{H} 1$ cells. EndoC- $\beta \mathrm{H} 1$ cells were transfected with siCTRL (black bars) or with siRNAs targeting STAT2 (white bars), IRF9 (light-grey bars) or STAT2/IRF9 (dark-grey bars). Cells were left untreated or were treated with IFN $\alpha(2000 \mathrm{U} / \mathrm{ml})$ for $24 \mathrm{~h}$. mRNA expression of STAT2 (a), IRF9 (b), HLA-ABC (c), $C X C L 10$ (d), MXI (e), CHOP (f), ATF3 (g), BIP (h) and XBP1s (i) was

analysed by RT-PCR and normalised by $\beta$-actin, and then normalised by siCTRL (black bars treated with IFN $\alpha$ ), considered as 1 . Results are means \pm SEM of three or four independent experiments. ${ }^{*} p<0.05$, $* * p<0.01$ and $* * * p<0.001$ vs untreated and transfected with the same siRNA; ${ }^{\dagger} p<0.05,{ }^{\dagger \dagger} p<0.01$ and ${ }^{\dagger \dagger} p<0.001$, as indicated by bars (ANOVA)

and TYK2 in IFN signalling' and 'role of pattern recognition receptors in recognition of bacteria and virus' as the three top canonical pathways [23]. TYK2, a candidate gene for type 1 diabetes, regulates both PIC- (a mimic of double-stranded RNA produced during viral infection) and IFN $\alpha$-induced MHC class I expression and inflammation in human beta cells [23]. Furthermore, histological analysis and other approaches have identified higher expression of type I IFNs in islets from patients with type 1 diabetes [7-10], and self-reactive antibodies targeting type I IFNs are associated with protection against type 1 diabetes in patients with an autoimmune syndrome [20].

Three hallmarks of the pancreatic islets in early human type 1 diabetes are overexpression of HLA class I [1, 2], ER stress $[3,37]$ and beta cell apoptosis [6], and we presently show that IFN $\alpha$ induces or contributes to these three phenomena in human beta cells.

Combinations of the pro-inflammatory cytokines IL-1 $\beta$, $\mathrm{TNF} \alpha$ and IFN $\gamma$, which probably appear later in the progression of islet inflammation as compared with IFN $\alpha$, induce ER stress in beta cells. ER stress might contribute to the magnification of apoptotic pathways, exacerbation of inflammation and increased antigen presentation in the context of type 1

diabetes [26, 37, 38]. Here, we report for the first time that IFN $\alpha$ alone upregulates expression of several ER stress markers, including p-EIF2 $\alpha$, XBP1s, BIP, C/EBP homologous protein (CHOP) and ATF3. Although not sufficient by itself to induce beta cell death, ER stress contributes to human beta cell death when these cells are exposed to IFN $\alpha$ plus IL$1 \beta$, as demonstrated by the partial protection afforded by knockdown of the pro-apoptotic transcription factor CHOP or co-culture of the cells with the chemical chaperone TUDCA (present data). Importantly, TUDCA administration was found to provide protection against diabetes in two mouse models of the disease [5].

Data from other tissues have already indicated a possible crosstalk between type I IFNs and ER stress: ER stress enhances IFN $\beta$ induction in PIC-treated macrophages [39] and potentiates PIC-induced expression of IFN $\beta$ and other inflammatory cytokines in dendritic cells [40]. Furthermore, PICinduced overexpression of ISGs triggers ER stress in HeLa cells [41].

To better understand the mechanisms underlying IFN $\alpha$ mediated signalling in human beta cells, we silenced the different proteins involved in the type I IFN pathway (Fig. 8j), including TYK2, STATs, and IRF9. Inhibition of TYK2, a key 
Fig. 7 Inhibition of USP18 overstimulates type I IFN signalling and increases ER stress and inflammation markers in EndoC- $\beta \mathrm{H} 1$ cells. EndoC- $\beta \mathrm{H} 1$ cells were transfected with siCTRL (black bars) or with an siRNA targeting USP18 (siUSP18, white bars). Cells were left untreated or were treated with $\operatorname{IFN} \alpha(2000 \mathrm{U} / \mathrm{ml})$ for $24 \mathrm{~h}$. (a, $\mathbf{f}-$ l) mRNA levels of USP18 (a), $H L A-A B C$ (f), CXCL10 (g), MX1 (h), $C H O P(\mathbf{i}), A T F 3(\mathbf{j}), B I P(\mathbf{k})$ and $X B P 1 s$ (l) were analysed by RT-PCR and normalised by $\beta$ actin. In (a), values were normalised by the highest value of each experiment (considered as 1). (b-d) Protein expression was measured by western blot. Representative images of three independent experiments are shown (b) and densitometry results are presented for $\mathrm{p}$-STAT1 (c) and p-STAT2 (d). Values were normalised by $\alpha$-tubulin ( $\alpha$-tub), and then by the highest value of each experiment (considered as 1). (e) Apoptosis was evaluated using HO/PI staining. Results are means \pm SEM of three to five independent experiments. $* p<0.05, * * p<0.01$ and $* * * p<0.001$ vs untreated and transfected with the same siRNA; ${ }^{\dagger} p<0.05,{ }^{\dagger \dagger} p<0.01$ and ${ }^{\dagger \dagger} p<0.001$, as indicated by bars (ANOVA) a
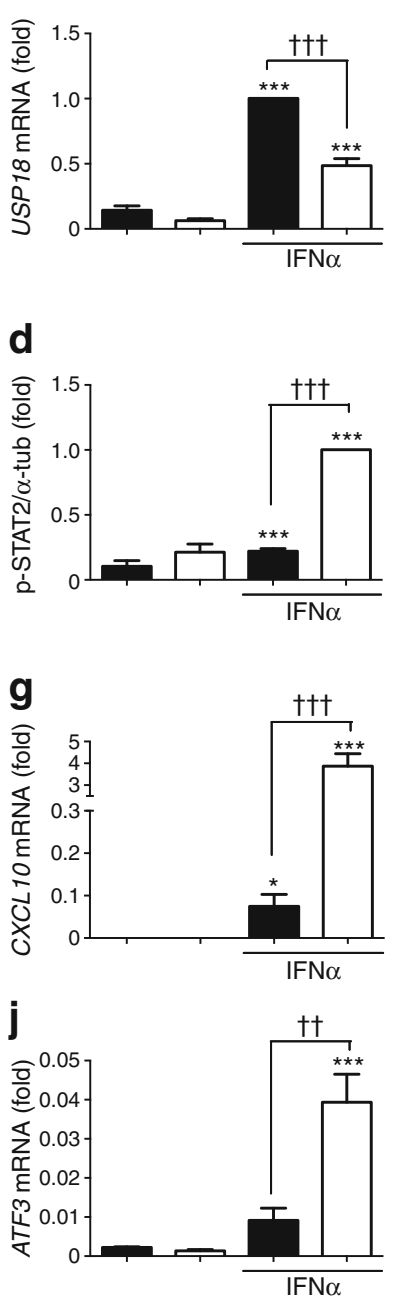

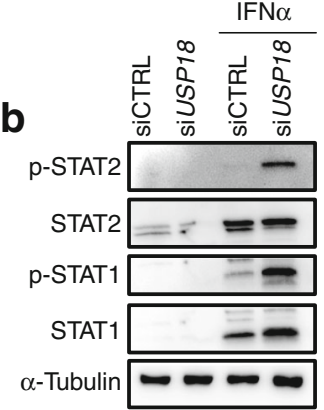

e

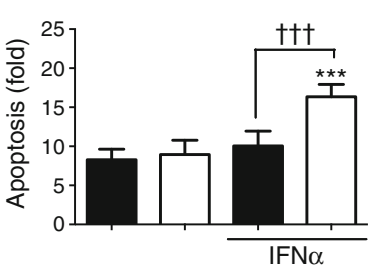

h

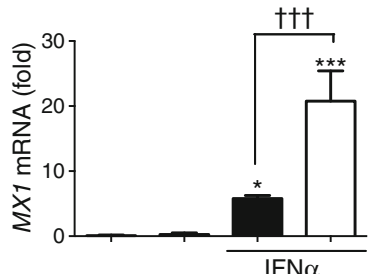

k

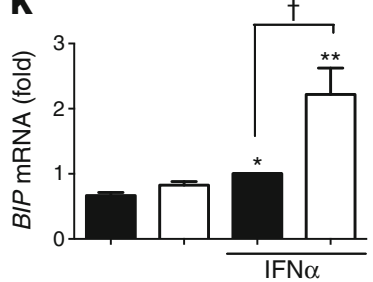

C
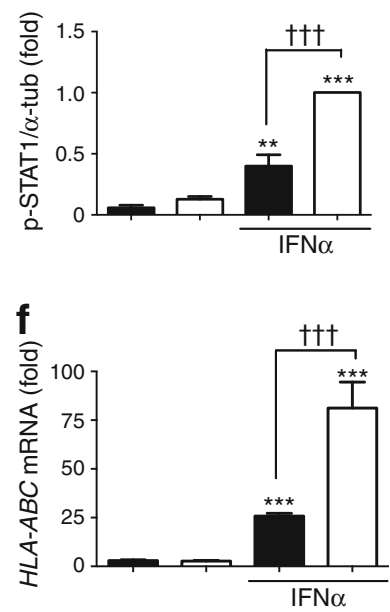

i

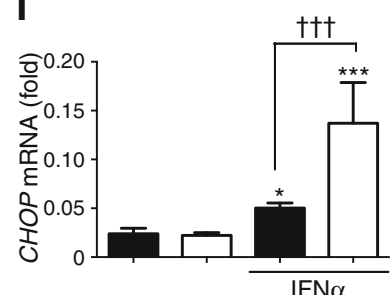

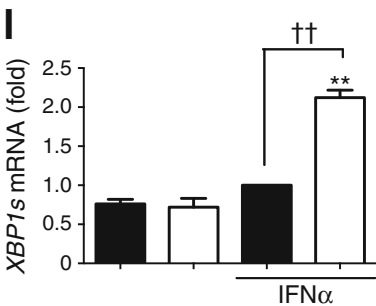

link between the type I IFN receptor and its downstream signalling, decreased IFN $\alpha$-induced expression of ER stress marker genes, mainly $C H O P$ and $A T F 3$, and prevented CXCL10 and MX1 expression. Inhibition of the transcription factors STAT2 and IRF9 prevented IFN $\alpha$-induced expression of HLA class I, and inflammation and ER stress markers, suggesting that these two proteins are critical for the activity of IFN $\alpha$ in beta cells. Unexpectedly, STAT1 inhibition not only failed to decrease the expression of these markers but also actually increased the expression of CXCL10, MX1 and ATF3. STAT1-silenced cells presented higher p-STAT2 expression, suggesting a compensatory activation of STAT2 once STAT1 is blocked, apparently increasing markers of inflammation and ER stress. The same was the case when STAT2 was blocked: there was an increase in STAT1 activation but in this case upregulation of STAT1 did not prevent inhibition of the downstream effects of IFN $\alpha$ (Figs 3 and 4). Primary murine macrophages deficient in STAT1, when exposed to Legionella pneumophila in the presence of type I IFNs, induce a complex between STAT2 and IRF9 that triggers a potent but delayed IFN response against the bacteria [33]. This indicates that both STATs are functionally redundant in macrophages [33]. Our present data, however, suggest that the roles of STAT1 and STAT2 are not redundant in beta cells, as the observed increase in STAT1 activation is not sufficient to compensate for the lack of STAT2.

A very recent study has shown that HLA hyperexpression is strongly correlated with STAT1 expression in beta cellcontaining islets from type 1 diabetes patients [1]. STAT2 was not investigated in this study. The present data suggest that STAT1 is important for IFN $\gamma$-induced HLA class I upregulation, but not for IFN $\alpha$, which acts mainly via STAT2. Collectively, these observations suggest that HLA overexpression in the islets of patients developing type 1 diabetes may be regulated by different mechanisms at different stages of the disease. In the early stage, IFN $\alpha$-induced HLA upregulation may require mostly the 
Fig. 8 IFN $\alpha$ acts synergistically with IL-1 $\beta$ to induce beta cell apoptosis. (a-h) EndoC- $\beta \mathrm{H} 1$ cells were left untreated (black bars) or were treated with IFN $\alpha$ (white bars) $(200,1000$ or 2000 $\mathrm{U} / \mathrm{ml}$ ), IL-1 $\beta$ (light grey bars) (5, 25 or $50 \mathrm{U} / \mathrm{ml}$ ) or a combination of both (dark grey bars) for $24 \mathrm{~h}$. (i) Dispersed human islets were left untreated (black bars) or were treated with IFN $\alpha$ (white bars) (2000 U/ml), IL-1 $\beta$ (light grey bars) $(50 \mathrm{U} / \mathrm{ml})$ or a combination of both (dark grey bars) for $24 \mathrm{~h}$. Apoptosis was evaluated using $\mathrm{HO} / \mathrm{PI}$ staining (a, i). mRNA levels of $H L A-A B C$ (b), CXCL10 (c), $M X 1$ (d), $C H O P(\mathbf{e}), A T F 3$ (f), $B I P(\mathbf{g})$ and $X B P 1 s(\mathbf{h})$ were analysed by RT-PCR and normalised by $\beta$-actin. Results are means \pm SEM of four to six independent experiments. $* p<0.05, * * p<0.01$ and $* * * p<0.001$ vs untreated; ${ }^{\dagger} p<0.01$ and ${ }^{\dagger \dagger} p<0.001$, as indicated by bars (ANOVA). (j) Proposed model for the role of IFN $\alpha$ in pancreatic beta cells. JAK1, Janus kinase 1; IFN $\alpha$ R, IFN $\alpha / \beta$ receptor
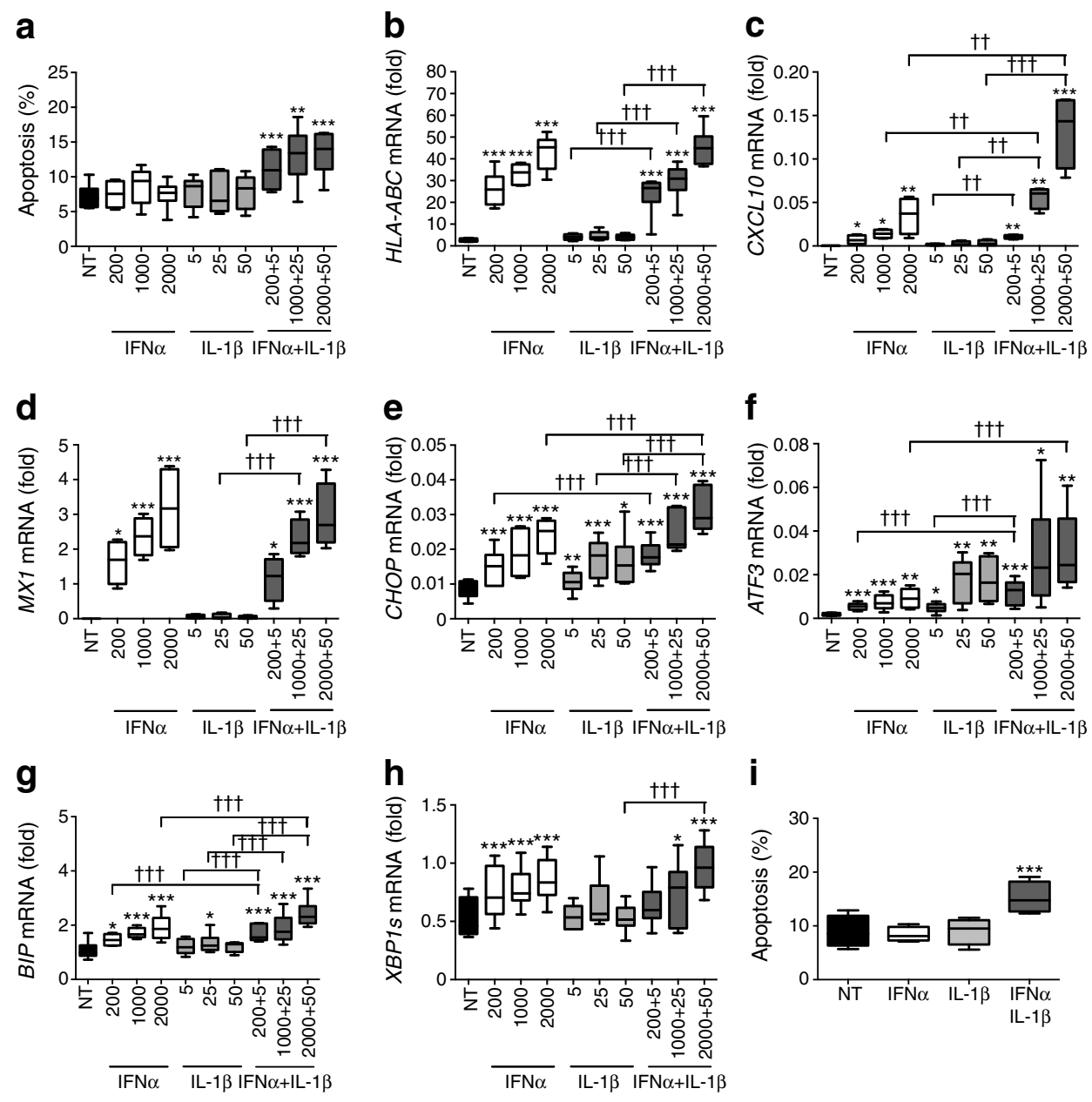

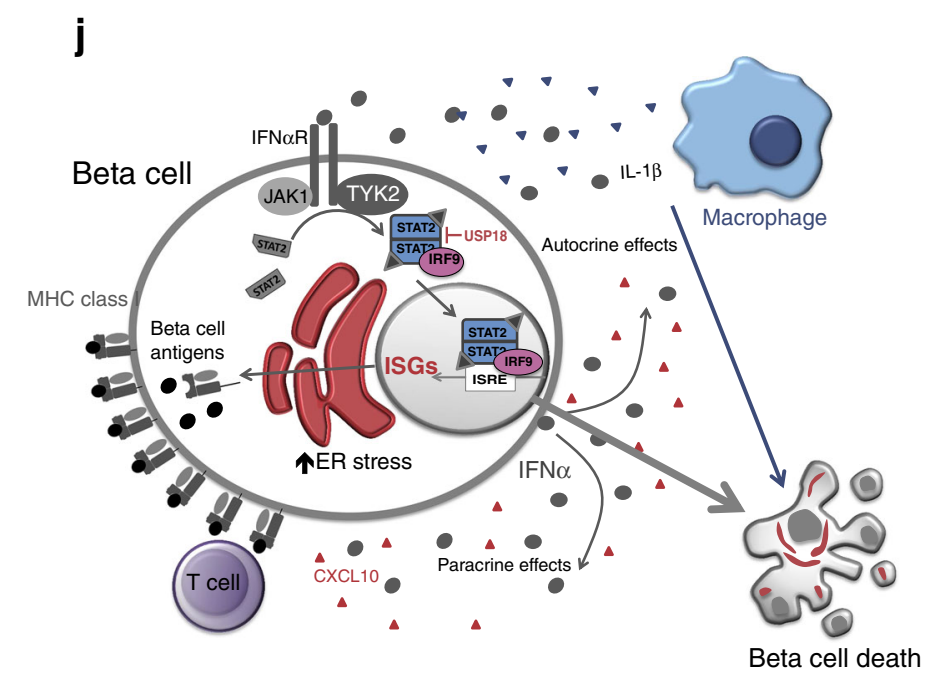

TYK2-STAT2-IRF9 axis, while at a later stage there may be a second wave of induction promoted by immune-cell-produced IFN $\gamma$ via STAT1 and downstream mediators.

Taken together, the above observations indicate that the following steps are crucial for IFN $\alpha$ signalling in beta cells (Fig. 8j). Upon exposure to 'danger signals' (e.g. viral infection or other exogenous or endogenous mediators that remain to be determined; [10,36, 42, 43]), production and release of type I IFNs (IFN $\alpha / \beta)$ is triggered in beta cells and neighbour cells, exerting both autocrine and paracrine effects. IFN $\alpha$ binds to the IFNAR1 and activates the type I IFN pathway, in which the TYK2-STAT2-IRF9 axis plays a critical 
role. This activation induces a massive expression of ISGs, hyperexpression of MHC class I proteins and an increase in the chemokine CXCL10. Conjunction of these factors with a genetic predisposition to type 1 diabetes (for instance, increased expression of TYK2) places the beta cells in a delicate situation: on one hand, the increase in CXCL10 expression attracts monocytes, $\mathrm{T}$ lymphocytes and natural killer cells [6], and on the other, upregulation of MHC class I and the putative induction of modified autoantigens by ER stress increases the efficiency of presentation of beta cell antigens to the immune cells [44]. All these effects may be secondary to local release of IFN $\alpha$. Importantly, IFN $\alpha$ also sensitises beta cells to IL-1 $\beta$ released by activated macrophages during early insulitis, increasing beta cell death and consequent antigen presentation. This places IFN $\alpha$ as a central modulator of excessive inflammatory and ER stress responses in the early stages of type 1 diabetes, contributing to the progressive destruction of pancreatic beta cells and to the triggering of autoimmunity in genetically predisposed individuals. Thus, targeting IFN $\alpha$ in type 1 diabetes may be a promising adjuvant therapy in the very early stages of the disease.

Acknowledgements The authors are grateful to M. Pangerl, A. M. Musuaya, N. Pachera and I. Millard of the ULB Center for diabetes research, Université Libre de Bruxelles, Belgium, for excellent technical support.

Data availability The data that support the findings of this study are available from the corresponding authors (lmarroqu@ulb.ac.be and deizirik@ulb.ac.be) upon reasonable request.

Funding This work was supported by grants from the Fonds National de la Recherche Scientifique (FNRS), Belgium, the Horizon 2020 Program (T2Dsystems [GA667191]) and the NIH-NIDDK-HIRN Consortium 1UC4DK104166-01, USA to DLE. DLE and PM have received funding from the Innovative Medicines Initiative 2 Joint Undertaking under grant agreement No 115797 (INNODIA). This Joint Undertaking receives support from the Union's Horizon 2020 research and innovation programme and 'EFPIA', 'JDRF' and 'The Leona M. and Harry B. Helmsley Charitable Trust'. LM is supported by an FNRS postdoctoral fellowship.

Duality of interest The authors declare that there is no duality of interest associated with this manuscript.

Contribution statement LM and RSDS contributed to the original idea and the design of the experiments, researched data, contributed to the discussion and wrote, revised and edited the manuscript. AOdb, ACdB, LM and PM researched data and revised and edited the manuscript. DLE contributed to the original idea and the design and interpretation of the experiments, contributed to discussion and wrote, revised and edited the manuscript. All authors read and approved the manuscript, and gave informed consent for publication. LM and DLE are the guarantors of this work and, as such, had full access to all the data in the study and take responsibility for the integrity of the data and the accuracy of the data analysis.

\section{References}

1. Richardson SJ, Rodriguez-Calvo T, Gerling IC et al (2016) Islet cell hyperexpression of HLA class I antigens: a defining feature in type 1 diabetes. Diabetologia 59:2448-2458

2. Richardson SJ, Morgan NG, Foulis AK (2014) Pancreatic pathology in type 1 diabetes mellitus. Endocr Pathol 25:80-92

3. Marhfour I, Lopez XM, Lefkaditis D et al (2012) Expression of endoplasmic reticulum stress markers in the islets of patients with type 1 diabetes. Diabetologia 55:2417-2420

4. Tersey SA, Nishiki Y, Templin AT et al (2012) Islet $\beta$-cell endoplasmic reticulum stress precedes the onset of type 1 diabetes in the nonobese diabetic mouse model. Diabetes 61:818-827

5. Engin F, Yermalovich A, Nguyen T et al (2013) Restoration of the unfolded protein response in pancreatic $\beta$ cells protects mice against type 1 diabetes. Sci Transl Med 5:211 ra156

6. Eizirik DL, Colli ML, Ortis F (2009) The role of inflammation in insulitis and $\beta$-cell loss in type 1 diabetes. Nat Rev Endocrinol 5: 219-226

7. Huang X, Yuang J, Goddard A et al (1995) Interferon expression in the pancreases of patients with type I diabetes. Diabetes 44:658-664

8. Somoza N, Vargas F, Roura-Mir C et al (1994) Pancreas in recent onset insulin-dependent diabetes mellitus. Changes in HLA, adhesion molecules and autoantigens, restricted $\mathrm{T}$ cell receptor $\mathrm{V}$ beta usage, and cytokine profile. J Immunol 153:1360-1377

9. Foulis AK, Farquharson MA, Meager A (1987) Immunoreactive $\alpha$ interferon in insulin-secreting $\beta$ cells in type 1 diabetes mellitus. Lancet 2:1423-1427

10. Dotta F, Censini S, van Halteren AG et al (2007) Coxsackie B4 virus infection of $\beta$ cells and natural killer cell insulitis in recentonset type 1 diabetic patients. Proc Natl Acad Sci U S A 104:51155120

11. Kay TW, Campbell IL, Oxbrow L, Harrison LC (1991) Overexpression of class I major histocompatibility complex accompanies insulitis in the non-obese diabetic mouse and is prevented by anti-interferon-gamma antibody. Diabetologia 34:779-785

12. Li Q, Xu B, Michie SA, Rubins KH, Schreriber RD, McDevitt HO (2008) Interferon- $\alpha$ initiates type 1 diabetes in nonobese diabetic mice. Proc Natl Acad Sci U S A 105:12439-12444

13. Li Q, McDevitt HO (2011) The role of interferon alpha in initiation of type I diabetes in the NOD mouse. Clin Immunol 140:3-7

14. Kallionpaa H, Elo LL, Laajala E et al (2014) Innate immune activity is detected prior to seroconversion in children with HLA-conferred type 1 diabetes susceptibility. Diabetes 63:2402-2414

15. Ferreira RC, Guo H, Coulson RM et al (2014) A type I interferon transcriptional signature precedes autoimmunity in children genetically at risk for type 1 diabetes. Diabetes 63:2538-2550

16. Pujol-Borrell R, Todd I, Doshi M, Gray D, Feldmann M, Bottazzo GF (1986) Differential expression and regulation of MHC products in the endocrine and exocrine cells of the human pancreas. Clin Exp Immunol 65:128-139

17. Richardson SJ, Willcox A, Bone AJ, Morgan NG, Foulis AK (2011) Immunopathology of the human pancreas in type-I diabetes. Semin Immunopathol 33:9-21

18. Lundberg M, Krogvold L, Kuric E, Dahl-Jorgensen K, Skog O (2016) Expression of interferon-stimulated genes in insulitic pancreatic islets of patients recently diagnosed with type 1 diabetes. Diabetes 65:3104-3110

19. Stewart TA, Hultgren B, Huang X, Pitts-Meek S, Hully J, MacLachlan NJ (1993) Induction of type I diabetes by interferonalpha in transgenic mice. Science 260:1942-1946

20. Meyer S, Woodward M, Hertel C et al (2016) AIRE-deficient patients harbor unique high-affinity disease-ameliorating autoantibodies. Cell 166:582-595 
21. Rhodes CJ, Taylor KW (1984) Effect of human lymphoblastoid interferon on insulin synthesis and secretion in isolated human pancreatic islets. Diabetologia 27:601-603

22. Lind K, Richardson SJ, Leete P, Morgan NG, Korsgren O, Flodstrom-Tullberg M (2013) Induction of an antiviral state and attenuated coxsackievirus replication in type III interferon-treated primary human pancreatic islets. J Virol 87:7646-7654

23. Marroqui L, Dos Santos RS, Floyel T et al (2015) TYK2, a candidate gene for type 1 diabetes, modulates apoptosis and the innate immune response in human pancreatic beta cells. Diabetes 64: 3808-3817

24. Ravassard P, Hazhouz Y, Pechberty S et al (2011) A genetically engineered human pancreatic $\beta$ cell line exhibiting glucoseinducible insulin secretion. J Clin Invest 121:3589-3597

25. Eizirik DL, Pipeleers DG, Ling Z, Welsh N, Hellerstrom C, Andersson A (1994) Major species differences between humans and rodents in the susceptibility to pancreatic $\beta$ cell injury. Proc Natl Acad Sci U S A 91:9253-9256

26. Brozzi F, Nardelli TR, Lopes M et al (2015) Cytokines induce endoplasmic reticulum stress in human, rat and mouse beta cells via different mechanisms. Diabetologia 58:2307-2316

27. Benner C, van der Meulen T, Caceres E, Tigyi K, Donaldson CJ, Huising MO (2014) The transcriptional landscape of mouse beta cells compared to human beta cells reveals notable species differences in long non-coding RNA and protein-coding gene expression. BMC Genomics 15:620

28. Martens GA (2015) Species-related differences in the proteome of rat and human pancreatic beta cells. J Diabetes Res 2015:549818

29. Santin I, Dos Santos RS, Eizirik DL (2016) Pancreatic beta cell survival and signaling pathways: effects of type 1 diabetesassociated genetic variants. Methods Mol Biol 1433:21-54

30. Marroqui L, Santin I, Dos Santos RS, Marselli L, Marchetti P, Eizirik DL (2014) BACH2, a candidate risk gene for type 1 diabetes, regulates apoptosis in pancreatic $\beta$-cells via JNK1 modulation and crosstalk with the candidate gene PTPN2. Diabetes 63:25162527

31. Overbergh L, Valckx D, Waer M, Mathieu C (1999) Quantification of murine cytokine mRNAs using real time quantitative reverse transcriptase PCR. Cytokine 11:305-312

32. Gonzalez-Navajas JM, Lee J, David M, Raz E (2012) Immunomodulatory functions of type I interferons. Nat Rev Immunol 12:125-135
33. Abdul-Sater AA, Majoros A, Plumlee CR et al (2015) Different STAT transcription complexes drive early and delayed responses to type I IFNs. J Immunol 195:210-216

34. Santin I, Moore F, Grieco FA, Marchetti P, Brancolini C, Eizirik DL (2012) USP18 is a key regulator of the interferon-driven gene network modulating pancreatic beta cell inflammation and apoptosis. Cell Death Dis 3, e419

35. Miani M, Colli ML, Ladriere L, Cnop M, Eizirik DL (2012) Mild endoplasmic reticulum stress augments the proinflammatory effect of IL- $1 \beta$ in pancreatic rat $\beta$-cells via the IRE1 $\alpha / \mathrm{XBP} 1 \mathrm{~s}$ pathway. Endocrinology 153:3017-3028

36. Op de beeck A, Eizirik DL (2016) Viral infections in type 1 diabetes mellitus - why the $\beta$ cells? Nat Rev Endocrinol 12:263-273

37. Eizirik DL, Miani M, Cardozo AK (2013) Signalling danger: endoplasmic reticulum stress and the unfolded protein response in pancreatic islet inflammation. Diabetologia 56:234-241

38. Eizirik DL, Cardozo AK, Cnop M (2008) The role for endoplasmic reticulum stress in diabetes mellitus. Endocr Rev 29:42-61

39. Smith JA, Turner MJ, DeLay ML, Klenk EI, Sowders DP, Colbert RA (2008) Endoplasmic reticulum stress and the unfolded protein response are linked to synergistic IFN- $\beta$ induction via $\mathrm{X}$-box binding protein 1. Eur J Immunol 38:1194-1203

40. $\mathrm{Hu} \mathrm{F}, \mathrm{Yu} \mathrm{X}$, Wang $\mathrm{H}$ et al (2011) ER stress and its regulator X-boxbinding protein-1 enhance polyIC-induced innate immune response in dendritic cells. Eur J Immunol 41:1086-1097

41. Cheng J, Liao Y, Zhou L, Peng S, Chen H, Yuan Z (2016) Amplified RLR signaling activation through an interferonstimulated gene-endoplasmic reticulum stress-mitochondrial calcium uniporter protein loop. Sci Rep 6:20158

42. Richardson SJ, Leete P, Bone AJ, Foulis AK, Morgan NG (2013) Expression of the enteroviral capsid protein VP1 in the islet cells of patients with type 1 diabetes is associated with induction of protein kinase R and downregulation of Mcl-1. Diabetologia 56:185-193

43. Krogvold L, Edwin B, Buanes T et al (2015) Detection of a lowgrade enteroviral infection in the islets of langerhans of living patients newly diagnosed with type 1 diabetes. Diabetes 64:16821687

44. Phelps EA, Cianciaruso C, Michael IP et al (2016) Aberrant accumulation of the diabetes autoantigen GAD65 in Golgi membranes in conditions of ER stress and autoimmunity. Diabetes 65:26862699 